\title{
Editorial
}

\section{Update on lung disease in coalminers}

The best known disabling chronic lung diseases of coalminers are progressive massive fibrosis, a wholly occupational disease, and chronic airflow obstruction, a partial one. This editorial briefly reviews recently completed studies that have furthered our understanding of progressive massive fibrosis and have enabled direct estimates to be made of the risk of the disease in relation to exposure to measured concentrations of respirable dust. The influence of exposure to quartz on pneumoconiosis in coalminers and the importance of irregular opacities are considered. The evidence that airflow obstruction in coalminers, long the subject of debate, does result from exposure to respirable dust, and that dust related lung functional impairment may be severe in some individuals is also discussed.

Much of the work quoted here is based on British Coal's pneumoconiosis field research and other studies carried out by the Institute of Occupational Medicine. The purpose of this research programme is to provide quantitative information on the risks of respiratory disease in relation to airborne dust, on which preventive measures may be based. The main strength of this research and the reason it is quoted extensively here lies in its extraordinarily detailed long term programme of measurements of airborne dust concentrations, which, linked to similarly detailed, and compatible, occupational records enable precise estimates of individual cumulative exposures to respirable dust to be calculated. By this means the demonstration of dust exposure/medical response relations has advanced our knowledge of the qualitative and quantitative effects of airborne dust.

\section{Progressive massive fibrosis}

Progressive massive fibrosis (complicated pneumoconiosis) of coalworkers is associated with breathlessness, ${ }^{1}$ impaired lung function, ${ }^{23}$ and increased mortality..$^{4-7}$ In the coal industry the strategy of prevention of progressive massive fibrosis has been based on the observation by Cochrane that the condition is much more likely to occur in men who already have simple pneumoconiosis than in those without. ${ }^{8}$ Since the risk appeared to be predominantly in men with category 2 or 3 simple pneumoconiosis, and much less in men with category 1 , dust control measures have been directed towards reducing the likelihood of a man developing category 2 simple pneumoconiosis in the hope that this would also reduce the incidence of progressive massive fibrosis. Airborne dust control regulations intended to prevent category 2 simple pneumoconiosis are based on estimates of dust/disease relations established by British Coal's pneumoconiosis field research. ${ }^{9} 10$

These dust control measures have been successful in reducing the prevalence of both simple pneumoconiosis and of progressive massive fibrosis. Although new cases of both these do still occur, the prevalence of category 1 or greater simple pneumoconiosis and of progressive massive fibrosis in the current workforce of a selection of British collieries in 1984 were $1 \cdot 5 \%$ and $0 \cdot 1 \%$, respectively, compared with $8 \cdot 3 \%$ and $0 \cdot 8 \%$ in $1962 .{ }^{11}$ Whereas selective loss of men ${ }^{12}$ partly due to contraction of the industry has contributed to this change, there is strong evidence also of a decline in incidence of new cases of simple pneumoconiosis. ${ }^{13}$ This represents a considerable achievement in disease prevention.

The estimates of risk of simple pneumoconiosis were based on studies of working miners, and since men may leave work on account of ill health, it was not known until recently whether the estimates properly represented the risks in all miners, including those who leave the industry. New information on this has been provided by a follow up study of British miners who were working in the industry in the 1950s and were restudied 22 years later whether or not they were still working in mining. Men who left the industry did indeed have higher frequencies of pneumoconiosis than men who stayed, ${ }^{1214}$ confirming that ill health was one reason for their leaving. The relations, however, between cumulative exposure to respirable dust and risk of simple pneumoconiosis were similar in men who left and men who stayed, ${ }^{14}$ confirming the validity of the previous estimates of risk. ${ }^{10}$

This study also showed that men may develop progressive massive fibrosis for the first time after leaving the industry, ${ }^{10}$ whereas simple pneumoconiosis appears not to alter much on aggregate after exposure to dust has ceased. ${ }^{12}$ In this and another study ${ }^{15}$ the risk of men with category 1 simple pneumoconiosis developing progressive massive 
fibrosis appears more substantial than shown in previous work. ${ }^{816}$ Furthermore, it has been pointed out that whereas the incidence of progressive massive fibrosis is low among miners with little or no simple pneumoconiosis, the large size of the group means that it contributes about half of the cases of progressive massive fibrosis that do occur. ${ }^{17}$ This evidence suggests that the scientific basis for the prevention strategy (based on reducing the incidence of category 2 simple pneumoconiosis) is not as reliable as was thought.

A direct estimate of the risk of progressive massive fibrosis in relation to measured exposure to respirable dust would enable a prevention programme to be more soundly based, and fortunately a study of this condition in British miners has just been completed. Much information on the factors influencing the development of progressive massive fibrosis has been published in report form, ${ }^{15}$ and from this work an estimate of risk in relation to cumulative exposure to respirable dust has been made. ${ }^{18} \mathrm{~A}$ further study is planned of the reasons why this estimate indicates that the risk of PMF in response to a range of exposures to mixed respirable dust is slightly greater than the previously estimated risks of developing category 2 simple pneumoconiosis. ${ }^{10}$ When fully understood, this new information may lead to a review of the prevention strategy.

\section{Quartz and pneumoconiosis}

The average concentrations of quartz in the respirable dust in British coalmines are generally less than $10 \%$, and in these conditions quartz has not been shown to influence the risk of simple pneumoconiosis over and above the risk attributable to exposure to mixed dust. ${ }^{10}$ There are some exceptions to this which suggest, not surprisingly, that quartz may be important when its concentrations in the airborne dust are much higher than the average. For instance some men in one colliery where quartz concentrations in the coalface dust were unusually high as a result of adverse mining conditions have developed an unusually rapidly progressive pneumoconiosis. ${ }^{19}$ Another study of men whose simple pneumoconiosis progressed unusually rapidly, in many cases to progressive massive fibrosis, indicated that exposure to quartz had contributed to their disease. ${ }^{1020}$ The role of quartz is being further investigated by attempts to distinguish by the chest radiographic appearances between quartz related and coal related progressive massive fibrosis ${ }^{21}$ and by a study in progress of exposure/response relations in miners who have been exposed to unusual proportions of quartz in the respirable dust. Quantitative information on safe levels of airborne quartz when the pro- portion of quartz in the dust is high is urgently needeco to aid decisions on dust control limits.

\section{Irregular opacities}

The ILO scheme for recording the chest radiographi 흔 appearances of pneumoconiosis distinguishes between small opacities that are rounded in shape and thos® that are irregular. ${ }^{22}$ Until recently, studies of coalworkers' pneumoconiosis have considered only rounded opacities, though there is now evidence that irregular opacities are also related to dusE exposure. ${ }^{23-25}$ These opacities differ from rounded opacities in that they are related to an impairment of lung function, ${ }^{232627}$ and have been shown to be related to the presence of emphysema and fibrosis in necropsy material. ${ }^{28}$

Since disease prevention strategy is based on the $\vec{E}$ relations of small rounded opacities with dus? exposure, this new information on irregular opacities could have important implications. Further studies of irregular opacities are in progress.

\section{Chronic airflow obstruction}

The longstanding debate on "occupational bronchi: tis" (or "industrial bronchitis") refers to the chroniog inflammatory or degenerative effects of dust on the lung, excluding pneumoconiosis. These processes are्d usually assessed by such features as symptoms of chronic bronchitis, measurements of lung function? and necropsy studies of emphysema or mucous glan $\vec{\delta}$ hypertrophy.

An important chapter in the debate has been com pleted by a series of studies in which features o? chronic inflammation or degeneration of the lung irg several different industrial populations have been compared with quantitative estimates (based oro detailed measurements) of lifetime individuap. exposures to airborne dust. These, summarised in recent review, ${ }^{29}$ include several separate cross sec $₹$ tional studies of British coalminers, ${ }^{30-32}$ South Afrio can goldminers, ${ }^{33}$ and United States ${ }^{34}$ and Wes? German $^{35}$ coalminers. All confirm that exposure to respirable dust is related to a reduction in lung func $\overline{\bar{N}}$ tion, even after allowing for the effects of smokingo Additionally, two longitudinal studies of change of lung function have shown that exposure to dust accel స్ erates the loss of function occurring with age. ${ }^{36}{ }^{37} \mathrm{I}_{\mathrm{b}}$ would take the most determined sceptic to refuse to acknowledge this weight of evidence that exposure to: dust impairs lung function. Another study has shown that symptoms of chronic bronchitis are also related to dust exposure. ${ }^{38}$

The next chapter in the debate, on whether the effects of dust are ever severe enough to be disabling 
is being written at present. There is already some evidence for an affirmative answer. A small group of British coalminers has been identified who showed severe effects of dust exposure on their lung function, a deficit of the order of $600 \mathrm{ml}$ of $\mathrm{FEV}_{1}$ for a moderately high lifetime exposure to dust. ${ }^{39}$ Severe effects of dust are confirmed by a large mortality study of British miners, ${ }^{7}$ which showed that death from respiratory disease was related to lifetime exposure to respirable dust, not only for pneumoconiosis but also for the certified causes "chronic bronchitis and emphysema." Whereas the diagnostic difficulties of death certification are well recognised, it is highly probable that the causes of death in the latter categories were from chronic inflammatory and degenerative conditions.

Thus there is already some good evidence that the chronic inflammatory and degenerative effects of dust on the lung may occasionally be severe enough to cause disability and premature death. Studies in other industrial populations might help to confirm these results. Important questions which remain to be answered include the further characterisation of these effects of dust in terms of clinical features, pathology, and pathogenesis, and what measures are required to prevent men from being disabled.

In general, dust exposure appears to affect the forced vital capacity at least as much as the FEV $_{1},{ }^{29} 3140$ a different pattern of abnormality from the classic airflow obstruction induced by smoking. This suggests an element of a restrictive lung defect as well as airflow obstruction. Some workers have suggested that airflow limitation occurs in the upper airways, but their data also show a parallel reduction of $\mathrm{FEV}_{1}$ and FVC. ${ }^{40}$ Men. however, who show severe effects of dust exposure ${ }^{31} 39$ most of whom have smoked, have severe airflow obstruction, and in many cases are clinically indistinguishable from men whose disease is entirely attributable to smoking.

There is an incomplete picture of the underlying pathological abnormalities which account for these functional defects. A necropsy study has shown that emphysema is more common in miners than in a comparable population of non-miners, ${ }^{41}$ confirming the conclusions of an earlier much criticised study, ${ }^{42}$ and another has shown that the likelihood of the presence of centrilobular emphysema in coalminers' lungs is related to exposure to respirable dust. ${ }^{43}$ Yet the pattern of the dust related functional defect would suggest that one or more other processes occur in addition to the emphysema, to account for the restrictive component of the defect. Perhaps such processes should be sought in the region of the respiratory bronchiole. where abnormalities have been described in workers exposed to mineral dusts other than coal. ${ }^{44}$
It is probable that dust control measures designed to prevent pneumoconiosis also aid the prevention of occupational bronchitis. Studies in progress will enable the estimation of exposure/response relations for lung function which will help to review the adequacy of present dust control measures. A minority of individuals who are extremely susceptible to the effects of dust, however, may be difficult to protect by general measures, and it would be helpful to identify these individuals before they have developed severe functional impairment. It has already been shown that miners with unusually rapid loss of function may be identified by serial spirometric measurements, before they become frankly abnormal, ${ }^{45}$ and the best adjunct to general dust control measures would seem to be serial measurements of lung function in all men in dusty occupations to identify and advise those who appear to be suffering from an unusually rapid decline of function.

Institute of Occupational Medicine,

CA SOUTAR Edinburgh EH8 9SU, UK.

\section{References}

I Hart P d'A. Aslett EA. Chronic pulmonary disease in south Wales coalminers. I. Medical studies. B. Medical survey. London: Medical Research Council, 1942. (Special report series No 243.)

2 Gilson JC, Hugh Jones P. Lung function in coalworkers' pneumoconiosis. London: Medical Research Council, 1955. (Special report series No 290.)

3 Rogan JM, Ashford JR. Chapman PJ, Duffield DP. Fay JWJ, Rae S. Pneumoconiosis and respiratory symptoms in miners at eight collieries. Br Med J 1961;i:1337-42.

4 Stewart A. Pneumoconiosis of coalminers. A study of the disease after exposure to dust has ceased. $\mathrm{Br} J$ Ind $\mathrm{Med}$ 1948;5:120-40.

5 Cochrane AL. Carpenter RG. Moore F. Thomas J. The mortality of miners and ex-miners in the Rhondda Fach. Br J Ind Med 1964:21:38-45.

6 Oldham PD, Rossiter CE. Mortality in coalworkers' pneumoconiosis related to lung function: a prospective study. $\mathrm{Br} J$ Ind Med 1965;22:93-100.

7 Miller BG, Jacobsen M. Dust exposure, pneumoconiosis, and mortality of coalminers. Br J Ind Med 1985;42:723-33.

8 Cochrane AL. The attack rate of progressive massive fibrosis. $\mathrm{Br}$ $J$ Ind Med 1962;19:52-64.

9 Rogan TM, Rae S, Walton WH. The National Coal Board's pneumoconiosis field research-- an interim review. In; Davies CN. ed. Inhaled particles and vapours II. Oxford: Pergamon Press, 1967:493-508.

10 Hurley JF, Burns J, Copland L. Dodgson J, Jacobsen M. Coalworkers' simple pneumoconiosis and exposure to dust at 10 British coalmines. Br J Ind Med 1982:39:120-7.

11 National Coal Board Medical Service. Annual Report $1984-85$. London: National Coal Board. 1986.

12 Maclaren WM, Soutar CA. Progressive massive fibrosis and simple pneumoconiosis in ex-miners. Br J Ind Med 1985;42: 734-40.

13 Jacobsen M. Coalworkers' pneumoconiosis; results from epidemiological studies in Britain. In: Proceedings of the VIth International Pneumoconiosis Conference. Bochum 1983. Geneva: International Labour Office. 1984:92-102.

14 Soutar CA. Maclaren WM. Annis R. Melville AWT. Quan- 
titative relations between exposure to respirable coalmine dust and coalworkers' simple pneumoconiosis in men who have worked as miners but have left the coal industry. $\mathrm{Br} J$ Ind Med 1986:43:29-36.

15 Hurley JF, Maclaren WM, Alexander WP, et al. Factors influencing the occurrence of progressive massive fibrosis in British coalminers. Edinburgh: Institute of Occupational Medicine. 1984. (IOM report No TM/84/2.)

16 McLintock JS, Rae S, Jacobsen M. The attack rate of progressive massive fibrosis in British coalminers. In: Walton WH, ed. Inhaled particles III. Vol 2. Old Woking (Surrey): Unwin Bros. 1971:933-52.

17 Shennan DH, Washington JS, Thomas DJ, Dick JA, Kaplan YS, Bennett JG. Factors predisposing to the development of progressive massive fibrosis in coalminers. $\mathrm{Br} \mathrm{J}$ Ind $\mathrm{Med}$ 1981:38:321-6.

18 Hurley JF, Jacobsen M. Occupational hygiene implications of new results on progressive massive fibrosis in working coalminers. Annals of the American Conference of Government Industrial Hygienists (in press.)

19 Seaton A, Dick JA, Dodgson J, Jacobsen M. Quartz and pneumoconiosis in coalminers. Lancet 1981;ii:1272-5.

20 Jacobsen M, Maclaren WM. Unusual pulmonary observations and exposure to coalmine dust: a case-control study. In: Walton WH, ed. Inhaled particles $V$. Oxford: Pergamon Press. 1982:753-65.

21 Soutar CA, Collins HPR. Classification of progressive massive fibrosis of coalminers by type of radiographic appearance. $\mathrm{Br} J$ Ind Med 1984;41:334-9.

22 International Labour Office. Guidelines for the use of ILO international classification of radiographs of pneumoconiosis. Rev ed. (Occupational Safety and Health Series.) Geneva: International Labour Office, 1980.

23 Amandus HE, Lapp NL, Jacobsen G, Reger RB. Significance of irregular small opacities in radiographs of coalminers in the USA. Br J Ind Med 1976;33:13-7.

24 Cockcroft A, Lyons JP, Andersson N, Saunders MJA. Prevalence and relation to underground exposure of radiological irregular opacities in south Wales and workers with pneumoconiosis. Br J Ind Med 1983:40:169-72.

25 Dick JA, Jacobsen M, Gauld S, Pern PO. The significance of irregular opacities in the chest radiographs of British coalminers. In: Proceedings of the VIth International Pneumoconiosis Conference, Bochum 1983. Geneva: International Labour Office. 1984:283-99.

26 Cockcroft A, Berry G, Cotes JE, Lyons JP. Shape of small opacities and lung function in coalworkers. Thorax 1982;37:765-9.

27 Musk AW, Cotes JE. Bevan C, Campbell MJ. Relationship between types of simple coalworkers' pneumoconiosis and lung function. A nine-year follow-up study of subjects with small rounded opacities. Br J Ind Med 1981;38:313-20.

28 Cockcroft AE, Wagner JC, Seal RME, Lyons JP, Campbell MJ. Irregular opacities in coalworkers pneumoconiosiscorrelation with pulmonary function and pathology. Ann
Occup $H_{1} g$ 1981:26:767-87.

29 Soutar CA. Occupational bronchitis. In: Harrington $M$, ed Recent advances in occupational heath 3. London: Churchill: Livingstone (in press).

30 Rogan JM. Altield MD, Jacobsen M. Rae S. Walker DD Walton WH. Role of dust in the working environment in development of chronic bronchitis in British coalminers Br J Ind Med 1973:30:217-26.

31 Soutar CA. Hurley JF. Relation between dust exposure and lung function in miners and ex-miners. Br J Ind Med 1986:430 307-20.

32 Gauld SJ, Hurley JF. Miller BG. The effect of non-response in as longitudinal study of coalminers respiratory health and $\vec{O}$ exposure to dust. In: Proceedings of the sixth international sym-posium on inhaled particles, 1985. Cambridge: Britishw Occupational Hygiene Society (in press).

33 Wiles FJ, Faure MH. Chronic obstructive lung disease in gold miners. In: Walton WH. ed. Inhaled particles $\mathrm{IV}$. Oxford:3 Pergamon Press. 1977:727-35.

34 Hankinson M, Reger RB. Fairman RP. Lapp NL. Morgan WKC. Factors influencing expiratory flow rates in coal miners $\omega$ In: Walton WH, ed. Inhaled particles IV. Oxford: Pergamon $\vec{A}$ Press, 1977:737-55.

35 Reichel G, Ulmer WT. Results obtained by the variouso investigation centres: coalmine; active staff. In: Research report: chronic hronchitis and occupational dust exposure. $\overrightarrow{-}$ Deutsche Forschungmeinschaft. Boppard: Harald Boldt Verlag, 1978:237-47.

36 Love RG. Miller BG. Longitudinal study of lung function in coalminers. Thorax 1982:37:193-7.

37 Attfield MD. Longitudinal decline in FEV in United States coalminers. Thorax 1985;40:132-7.

38 Rae S, Walker DD, Attfield MD. Chronic bronchitis and dust exposure in British coalminers. In: Walton WH, ed. Inhaledo particles III. Old Woking (Surrey): Unwin Bros, 1971:837-81.

39 Hurley JF, Soutar CA. Can exposure to coalmine dust cause a severe impairment of lung function? $\mathrm{Br} J$ Ind Meckn 1986:43:150-7

40 Hankinson L, Reger RB, Morgan WKC. Maximal expiratory@ flows in coalminers. Am Rev Respir Dis 1977;116:175-80.

41 Cockcroft A, Seal RME, Wagner JC, et al. Post mortem study of emphysema in coalworkers and non-coalworkers. Lancet 1984:ii:600-3.

42 Ryder R, Lyons JP, Campbell H, Gough J. Emphysema in? coalworkers' pneumoconiosis. Br Med J 1970;iii:481-7.

43 Ruckley VA, Gauld SJ, Chapman JS, et al. Emphysema and dust exposure in a group of coal workers. Am Rev Respir Dis. 1984:129:528-32.

44 Churg A, Wright JL, Wiggs B, Parre PD, Largar N. Small air ways disease and mineral dust exposure. Prevalence, structure and function. Am Rev Respir Dis 1985;131:139-43.

45 Pern PO, Love RG, Wightman AJA, Soutar CA. Characteristics of coalminers who have suffered excessive loss of lung functiono over 10 years. Bull Eur Physiopathol Respir 1984;20:487-93. 